\title{
Reservoir and reservoir-less pressure effects on arterial waves in the canine aorta
}

\author{
Alessandra BORLOTTI ${ }^{\mathrm{a}}$, Chloe PARK ${ }^{\mathrm{a}}$, Kim H PARKER ${ }^{\mathrm{b}}$ and Ashraf W KHIR ${ }^{\mathrm{a}}$ \\ ${ }^{a}$ Brunel Institute for Bioengineering, Brunel University, Middlesex, UK. \\ ${ }^{\mathrm{b}}$ Department of Bioengineering, Imperial College London, London, UK.
}

Running head: Wave analysis with and without reservoir pressure

\section{Corresponding Author}

Ashraf W Khir

Reader in Cardiovascular Mechanics

Brunel Institute for Bioengineering

Brunel University

Uxbridge, Middx.

UB8 3PH

UK

Tel: +441895265857

Fax: +44 1895274608

Email: ashraf.khir@brunel.ac.uk

word count: 5931

number of tables: 3

number of figures: 4 


\begin{abstract}
A time domain approach to couple the Windkessel effect and wave propagation has been recently introduced. The technique assumes that the measured pressure in the aorta $(\mathrm{P})$ is the sum of a reservoir pressure $\left(\mathrm{P}_{\mathrm{r}}\right)$, due to the storage of blood, and an excess pressure $\left(\mathrm{P}_{\mathrm{e}}\right)$, due to the waves. Since the subtraction of $\mathrm{P}_{\mathrm{r}}$ from $\mathrm{P}$ results in a smaller component of $\mathrm{P}_{\mathrm{e}}$, we hypothesised that using the reservoir-wave approach would produce smaller values of wave speed and intensities. Therefore, the aim of this work is to quantify the differences in wave speed and intensity using $\mathrm{P}$, wave-only, and $\mathrm{P}_{\mathrm{e}}$, reservoir-wave techniques.

Pressure and flow were measured in the canine aorta in control condition and during total occlusion at four sites. Wave speed was determined using the PU-loop (c) and $\mathrm{P}_{\mathrm{e}} \mathrm{U}-$ loop $\left(\mathrm{c}_{\mathrm{e}}\right)$ methods, and WIA was performed using $\mathrm{P}$ and separately using $\mathrm{P}_{\mathrm{e}}$; the magnitude and time of the main waves and the reflection index were calculated.

Both analyses produced similar WIA curves, and no significant differences in the timing of the waves, except onset of the forward expansion wave, and indicated that distal occlusions have little effect on hemodynamics in the ascending aorta. We consistently found lower values of wave speed and intensities when the reservoir-wave model was applied. In particular, the magnitude of the backward waves was markedly smaller, even during proximal occlusions. In the absence of other independent techniques or evidence it is not currently possible to decide which of the two models is more correct.
\end{abstract}

Keywords: reservoir-wave model, wave speed, wave intensity analysis, reflected waves. 


\section{Introduction}

The cardiovascular hemodynamic has been extensively studied for several centuries $[1,2,3,4]$. One of the major representatives in the field at the end of the nineteenth century was Otto Frank who contributed to arterial mechanics with the mathematical formulation of the Windkessel effect [5]. The Windkessel model shows the importance of aortic compliance in turning the pulsatile cardiac output into a more steady flow in the microcirculation; about half of the stroke volume is stored during systole in the compliant arteries which recoil during diastole forwarding it through the microcirculation much more steadily [6]. The model consists of a resistance to flow through the microcirculation $(\mathrm{R})$ that depends on the peripheral vessels and a compliance $(\mathrm{C})$ determined mainly by the elasticity of the large arteries. The model predicts that the arterial pressure will decay exponentially during diastole with a time constant RC. The Windkessel model, as originally presented, describes the diastolic part of the pressure waveform very well, but is not accurate for systole because it does not take into account the contribution of waves [7]. The addition of the characteristic impedance to the two-element Windkessel was proposed to link the lumped model and the wave propagation in the arterial system $[8,9]$.

Another technique for studying arterial waves is wave intensity analysis (WIA), which is a time-domain technique based on the classical one-dimensional flow equations in flexible tubes, and was introduced as an alternative to the frequency-domain techniques $[10,11]$. Both WIA and impedance methods can be used for the separation of pressure and flow waveforms into their forward and backward components; producing results that are almost identical [12]. WIA, however, has the advantage that it does not rely upon the assumption of periodicity that is essential for Fourier analysis techniques [13]. WIA has been extensively used in the human aorta [14], in the radial vessels [15] and more recently 
noninvasively in the carotid artery [16]. Whilst WIA seems to describe the pattern of waves and their intensities very well, the aortic "reservoir effect" is not taken into account.

There are some anomalies in the separation of arterial pressure into its forward and backward components using either impedance or wave intensity analysis [12]. This is particularly noticeable during diastole when inflow into the proximal aorta is nearly zero, but pressure decays exponentially. Thus, any linear separation technique, such as WIA or impedance analysis will result in forward and backward pressure with nearly equal magnitudes in this period. This could be realised by standing waves in the aorta, but other evidence, such as the extended exponential pressure decay during extended diastole due to ectopic or missing heart beats, mitigates against them (Figure 6, in [17]).

The first time-domain approach to couple the reservoir effect and the wave propagation theory at the aortic root was proposed by Wang et al. [17]. The reservoir-wave model was extended to the venous system [18] and was further developed for any arbitrary location in the arterial system [19]. This model is based on the heuristic assumption that the measured pressure in the aorta $(\mathrm{P})$ is the sum of a reservoir pressure $\left(\mathrm{P}_{\mathrm{r}}\right)$, due to the storage of blood in the compliant aorta during systole and its discharge in diastole, and an excess pressure $\left(\mathrm{P}_{\mathrm{e}}\right)$, due to the waves. This new approach resolves the self-cancelling waves that appear in the separation of the flow waveforms using the measured pressure [20,21]. The subtraction of the reservoir pressure, which accounts for the potential energy stored in the aorta, allows the study of wave propagation employing WIA using $\mathrm{P}_{\mathrm{e}}$ instead of $\mathrm{P}$. Since the Windkessel function seems to improve left ventricle relaxation [22] and coronary blood flow [23], the study of the buffering function of the aorta in terms of $\mathrm{P}_{\mathrm{r}}$ could be a useful tool to better understand the mechanics of the heart and the coronary circulation. The reservoir-wave model has been applied to human [24], animal [18] and numerical data [19]. 
Although the reservoir-wave model is based on the in vivo observations of uniform diastolic decay with a time lag downstream $t$, some authors have questioned the validity of this technique [25,26]. Mynard et al. [25] showed that the use of $P_{e}$ for determining the intensity of the waves leads to a reduction or elimination of the backward compression waves and to an increase or artefactual introduction of expansion waves. On the other hand Wang et al. [27] demonstrated that the wave pattern after subtraction of $\mathrm{P}_{\mathrm{r}}$ is more physiologically consistent than that calculated using traditional WIA. As a contribution to the on-going debate regarding the two models, we assessed in this work the similarities and differences between the results of two models, and considered physiological explanations based on the anatomy of the arterial system.

Previous works $[17,18]$ have shown that the reservoir-wave approach yields small values of backward waves in normal conditions. However, this approach has not been adequately investigated in the presence of large reflections that are quantified using the waveonly approach. Also, since the subtraction of the reservoir pressure from the measured pressure results in a pressure component due to waves, that is significantly different in shape than that measured at the same location [17], we hypothesised that using the reservoir-wave model would produce different values of wave speed, assessed by the PU-loop method, and intensity, assessed using WIA, than those produced using the measured pressure. Therefore, the aim of this work is thus to provide a detailed, quantitative study of the differences in wave speeds and wave intensities when arterial flow properties are calculated using $\mathrm{P}$, wave-only model, and using $\mathrm{P}_{\mathrm{e}}$, reservoir-wave model. The data are from measurements in the canine ascending aorta when the effects of total occlusion at four different sites were studied [14]. This enables us to study the effect of the reservoir pressure in normal conditions and in conditions where enhanced reflected waves are certain to be present, similar to those expected in pathophysiological conditions such as arterial stiffness and hypertension. 


\section{Material and Methods}

\section{A. Reservoir-wave model}

Wang et al. [17] proposed that the measured ascending aorta pressure can be considered as the sum of a reservoir pressure $\left(\mathrm{P}_{\mathrm{r}}\right)$ and an excess pressure $\left(\mathrm{P}_{\mathrm{e}}\right)$, where $\mathrm{P}_{\mathrm{r}}$ accounts for the Windkessel effect and $\mathrm{P}_{\mathrm{e}}$ accounts for wave effect.

$P(x, t)=P_{r}(t)+P_{e}(x, t)$

Following recent work [28], we define $\mathrm{P}(\mathrm{x}, \mathrm{t})=\mathrm{P}_{\mathrm{r}}(\mathrm{t}-\tau(\mathrm{x}))+\mathrm{P}_{\mathrm{e}}(\mathrm{x}, \mathrm{t})$ where $\tau(\mathrm{x})$ is the time of wave propagation from the aortic root $(\mathrm{x}=0)$ to the location $\mathrm{x}$ in the arterial system. Since $\tau=0$ at the aortic root, this definition is consistent with previous work [17] analysing flow in the aortic root, but extends the concept to other parts of the arterial system in a way that overcomes the obvious objection that the reservoir pressure cannot be uniform throughout the arterial system (as assumed in the simple Windkessel model) because arterial wave speeds are finite.

Conservation of mass requires

$\frac{d V_{r}}{d t}=Q_{\text {in }}-Q_{\text {out }}$

where $\mathrm{V}_{\mathrm{r}}$ is the reservoir volume, $\mathrm{Q}_{\text {in }}$ is the aortic inflow and $\mathrm{Q}_{\text {out }}$ is the outflow. We assume that the aortic reservoir has a constant compliance, $\mathrm{C}$, and that the flow out of the arteries can be described by a simple resistance relationship

$Q_{\text {out }}(t)=\frac{P_{r}(t)-P_{\infty}}{R}$

where $\mathrm{P}_{\infty}$ is the asymptotic pressure of the diastolic exponential decay. This may be the venous pressure or may be determined by the interstitial pressure due to the waterfall effect. The mass conservation equation can then be written in terms of $\mathrm{P}_{\mathrm{r}}$

$$
\frac{d P_{r}(t)}{d t}+\frac{P_{r}(t)-P_{\infty}}{R C}=\frac{Q_{i n}(t)}{C}
$$


This has the general solution

$P_{r}(t)-P_{\infty}=\left(P_{0}-P_{\infty}\right) e^{-t / R C}+e^{-t / R C} \int_{t_{0}}^{t} \frac{Q_{i n}\left(t^{\prime}\right)}{C} e^{i / R C} d t^{\prime}$

where $\mathrm{t}_{0}$ and $\mathrm{P}_{0}$ are time and pressure at the beginning of the ejection. $\mathrm{Q}_{\text {in }}$ is zero during diastole by definition and so the reservoir pressure during diastole will simply fall exponentially. 1

The alternative arterial wave propagation theory (wave-only model) is derived from the onedimensional conservation of mass and momentum equations which can be solved by the method of characteristics [10]. This solution states that any disturbance in the vessel will generate wavefronts that travel in the forward and backward direction with speed $U \pm c$. Changes in pressure $(\mathrm{dP})$ and velocity $(\mathrm{dU})$ in these waves are related through the water hammer equation

$d P_{ \pm}= \pm \rho c d U_{ \pm}$

where $\rho$ is the fluid density, $\mathrm{c}$ the wave speed and " \pm " refers to the wave direction. The wave intensity, $\mathrm{dI}=\mathrm{dPdU}$, was introduced by Parker and Jones [10] as a measure of the energy flux carried by the waves.

Khir et al. [28] introduced the PU-loop method for the determination of $\mathrm{c}$ based on equation 6. If the wave speed (or equivalently the characteristic impedance) is known, it is possible to separate the measured pressure and velocity waveforms into their forward and backward components. This can be done either using impedance [30] or wave intensity analysis [10]. Using the water-hammer equation (equation 6) with the assumption that the forward and backward waves are additive, it can be shown that

$$
d P_{ \pm}(t)=\frac{1}{2}(d P(t) \pm \rho c d U(t)) ; \quad P_{ \pm}(t)=P_{0}+\sum_{t=0}^{t} d P_{ \pm}(t)
$$

where $\mathrm{P}_{0}$ is the integration constant chosen arbitrarily as diastolic pressure in the $(+)$ and zero in the (-) directions respectively. Also, 
$d U_{ \pm}(t)=\frac{1}{2}\left(d U(t) \pm \frac{1}{\rho c} d P(t)\right) ; \quad U_{ \pm}(t)=U_{0}+\sum_{0}^{t} d U_{ \pm}(t)$

where $\mathrm{U}_{0}$ is the integration constant taken as zero in both the $(+)$ and (-) directions.

It follows that the forward and backward wave intensity are

$d I_{ \pm}= \pm \frac{1}{4 \rho c}(d P \pm \rho c d U)^{2}$

Note that the separation technique depends upon the knowledge of the wave speed c.

\section{B. Experimental protocol}

Experiments were performed in 11 anaesthetised mongrel dogs (average weight $22 \pm$ $3 \mathrm{~kg}, 7$ males). The experimental protocol is described in Khir et al. [14]. The dogs were anaesthetised with sodium pentobarbital, $30 \mathrm{mg} / \mathrm{kg}$-body weight intravenously and a steady dose of $75 \mathrm{mg} / \mathrm{h}$ was given throughout the experiment. The dogs were endotracheally intubated and mechanically ventilated using a constant-volume ventilator (Model 607, Harvard Apparatus Company, Millis, MA, USA).

To measure flow rate an ultrasonic flow probe (Flow meter model T201, Transonic Systems Inc., Ithaca, NY, USA) was fitted around the ascending aorta approximately $1 \mathrm{~cm}$ distal to the aortic valve leaflets. Pressure at the aortic root, just downstream of the flow probe, was measured with a high-fidelity pressure catheter (Millar Instruments Inc., Houston, Texas, USA) inserted from the right or left brachial artery. Snares were placed at four different sites: the upper descending thoracic aorta at the level of the aortic valve (thoracic); the lower thoracic aorta at the level of the diaphragm (diaphragm); the abdominal aorta between the renal arteries (abdominal) and the left iliac artery, $2 \mathrm{~cm}$ downstream from the aorta iliac bifurcation (iliac). The right iliac artery was occluded throughout each experiment to allow for the insertion of a transducer-tipped pressure catheter used for measuring the pressure upstream each occlusion. Data were collected for $30 \mathrm{~s}$ before the occlusion (control) and during the occlusion; 3 min after the snare was applied. An interval of 10-15 min was 
allowed between each occlusion in order to return to control conditions [31]. The sequence of the four occlusions was varied between dogs using a 4X4 Latin-square to remove possible time effects. The circumference of the ascending aorta was measured post-mortem to derive the diameter required to convert the measured flow rate into velocity. All data were recorded at a sampling rate of $200 \mathrm{~Hz}$ and stored digitally. The relative time delay between $\mathrm{P}$ and $\mathrm{U}$ signals due to the phase differences of the transducers and to the small displacement between their locations was eliminated by the appropriate shifting of the velocity signal [32].

C. Analysis

The reservoir pressure was calculated using an algorithm similar to that described by Aguado-Sierra et al. [19]. Briefly, the start of diastole is defined as the time of the first point of inflection in the measured pressure after the systolic peak. The diastolic pressure is fitted to the model $\mathrm{P}(\mathrm{t})-\mathrm{P}_{\infty}=\left(\mathrm{P}_{0}-\mathrm{P}_{\infty}\right) \mathrm{e}^{-\mathrm{t} / \mathrm{RC}}$, where $\mathrm{P}_{0}$ is the pressure at the start of diastole, to find the time constant $\mathrm{RC}$ and the asymptotic pressure $\mathrm{P}_{\infty}$. The method is based on the two assumptions that (i) the arteries are well-matched for forward waves and (ii) the volume flow rate into the aorta is proportional to the excess pressure $\mathrm{P}_{\mathrm{e}}(\mathrm{t})$. The value of this constant of proportionality is determined iteratively by minimising the mean square error between the model and the measured pressure during the whole cardiac period. Given this constant, $\mathrm{P}_{\mathrm{r}}(\mathrm{t})$ and $\mathrm{P}_{\mathrm{e}}(\mathrm{t})$ can be calculated directly. In Table 1, the averaged values of measured pulse pressure $(\Delta \mathrm{P})$, reservoir pulse pressure $\left(\Delta \mathrm{P}_{\mathrm{r}}\right)$ and excess pulse pressure $\left(\Delta \mathrm{P}_{\mathrm{e}}\right)$ are reported together with the averaged value of diastolic pressure $\left(\mathrm{P}_{\mathrm{d}}\right)$.

Wave speed in the ascending aorta, was determined from the slope of the linear part of the PU-loop (c) and $\mathrm{P}_{\mathrm{e}} \mathrm{U}-$ loop $\left(\mathrm{c}_{\mathrm{e}}\right)$, before and during total occlusion. The net wave intensity was calculated using $\mathrm{P}(\mathrm{dI})$ and $\mathrm{P}_{\mathrm{e}}\left(\mathrm{dI}_{\mathrm{e}}\right)$ in all of the experimental conditions and then was separated in forward $\left(\mathrm{dI}_{+}, \mathrm{dI}_{\mathrm{e}^{+}}\right)$and backward $\left(\mathrm{dI}_{-}, \mathrm{dI}_{\mathrm{e}}\right)$ wave intensity. In all cases the forward wave intensity displayed a positive peak at the start of systole indicating a forward 
compression wave (FCW) and another at the end of systole indicating a forward expansion wave (FEW). In some conditions a negative peak in the backward wave intensity was discernible during mid-systole indicating a backward compression wave (BCW). The magnitude of the forward peaks $\left(\mathrm{dI}_{\mathrm{FCW}}, \mathrm{dI}_{\mathrm{eFCW}}\right.$ and $\left.\mathrm{dI}_{\mathrm{FEW}}, \mathrm{dI}_{\mathrm{eFEW}}\right)$ and backward peaks ( $\mathrm{dI}_{\mathrm{BCW}}, \mathrm{dI}_{\mathrm{eBCW}}$ ) and the Reflection Indices ( $\mathrm{RI}$ and $\mathrm{RI}_{\mathrm{e}}$ ), calculated as $\mathrm{dI}_{\mathrm{BCW}} / \mathrm{dI}_{\mathrm{FCW}}$ and $\mathrm{dI}_{\mathrm{eBCW}} / \mathrm{dI}_{\mathrm{eFCW}}$, were determined. Also, the time of the peaks $\left(\mathrm{t}_{\mathrm{FCW}}, \mathrm{t}_{\mathrm{eFCW}}, \mathrm{t}_{\mathrm{BCW}}, \mathrm{t}_{\mathrm{eBCW}}, \mathrm{t}_{\mathrm{FEW}}\right.$, $\left.t_{\mathrm{eFEW}}\right)$ and the onset time of the backward compression $\left(t_{\mathrm{BCW}} \mathrm{wnset}_{\mathrm{eBCWonset}}\right)$ and forward expansion waves $\left(t_{\text {FEWonset, }}, t_{\text {eFEWonset }}\right)$ were determined using the two models and the results were compared. Wave speed and intensity calculated with $\mathrm{P}$ and $\mathrm{P}_{\mathrm{e}}$ before and during the total occlusion are the average of all cardiac beats over the $30 \mathrm{~s}$ period of measurement. Four control recordings were sampled in each dog; one before each occlusion. Since there were no significant differences between these four control measurements, they were pooled for each dog and considered the control state. Data are presented in the text and tables as mean values $\pm \mathrm{SD}$ (mean was calculated by averaging the mean values of all dogs). Paired two-sided ttests were used to assess differences between parameters calculated using $\mathrm{P}$ and $\mathrm{P}_{\mathrm{e}}$. Paired ttests were also used to assess differences between parameters calculated during control and occlusion conditions. The relationship between $\Delta \mathrm{P}_{\mathrm{r}}$ and stroke volume $\left(\mathrm{V}_{\mathrm{in}}\right.$, calculated by integrating the area of under the flow waveform during systole) was assessed using bivariate correlation. Values of $\mathrm{p}<0.05$ were considered statistically significant. Statistical analyses were performed using SPSS 17.0 (SPSS Inc., Chicago, Illinois, USA). 


\section{Results}

\section{A. Wave speed}

There is a significant difference in the morphology of the $\mathrm{PU}$ and $\mathrm{P}_{\mathrm{e}} \mathrm{U}$ loops in all cases. The PU-loop is a distinct loop with large hysteresis between the systolic and diastolic portions of the curve. The $\mathrm{P}_{\mathrm{e}} \mathrm{U}$-loop exhibits much less hysteresis and in many cases, such as the control conditions shown in Figure 1, the loop collapsed almost completely to a single curve. In all cases, the early systolic portion of the loop was linear enabling a measurement of the wave speed from the slope. In every condition the wave speed determined from the PUloop, c, was greater than the wave speed determined from the $\mathrm{P}_{\mathrm{e}} \mathrm{U}-\mathrm{loop}, \mathrm{c}_{\mathrm{e}}$, and all of the differences were statistically significant. The values of $\mathrm{c}$ and $\mathrm{c}_{\mathrm{e}}$ and their ratio are reported for all conditions in Table 2. We see that $\mathrm{c}$ during the thoracic occlusion is significantly higher than control conditions $(9.9 \pm 2.5 \mathrm{~m} / \mathrm{s}$ vs. $6.0 \pm 2.6 \mathrm{~m} / \mathrm{s}, \mathrm{p}<0.05) . \mathrm{c}_{\mathrm{e}}$ calculated during the thoracic occlusion was not statistically different from control. There were no significant differences between either $\mathrm{c}$ or $\mathrm{c}_{\mathrm{e}}$ during any of the other occlusions compared to control conditions.

\section{B. Wave intensity and reflection index}

As seen in Figure 2, there were both similarities and differences between the wave intensity calculated with $\mathrm{P}, \mathrm{dI}=\mathrm{dPdU}$, and with $\mathrm{P}_{\mathrm{e}}, \mathrm{dI}_{\mathrm{e}}=\mathrm{dP}_{\mathrm{e}} \mathrm{dU}$. In all cases, the forward wave intensities, $\mathrm{dI}_{+}$and $\mathrm{dI}_{\mathrm{e}^{+}}$, were similar in shape with large peaks at the start $(\mathrm{FCW})$ and end (FEW) of systole. As discussed below, the morphology of these peaks was unchanged, but there were differences in their magnitudes. However, the backward wave intensities, dI. and $\mathrm{dI}_{\mathrm{e}-\text {, }}$ showed large differences with the no peaks discernible in the $\mathrm{dI}_{\mathrm{e}-}$ waveforms for many of the cases. The magnitude of the three main wave intensity peaks, $\mathrm{dI}_{\mathrm{FCW}}, \mathrm{dI}_{\mathrm{FEW}}$, $d I_{B C W}, \mathrm{dI}_{\mathrm{eFCW}}, \mathrm{dI}_{\mathrm{eFEW}}$ and $\mathrm{dI}_{\mathrm{eBCW}}$ and their ratios are reported in Table 2. For both of the forward waves, FCW and FEW, $\mathrm{dI}>\mathrm{dI}_{\mathrm{e}}$ and the difference is statistically significant in all 
cases except for the thoracic and diaphragm occlusions for the FEW wave. The results for the BCW are qualitatively different from the results for the forward waves. In all cases $\mathrm{dI}_{\mathrm{e}}<<\mathrm{dI}$ with the differences being highly significant statistically. The reflection index, which is related to the effective reflection coefficient, shows a similar pattern. For control conditions the difference between $\mathrm{RI}$ and $\mathrm{RI}_{\mathrm{e}}$ is large and statistically significant, as reported in Table 2.

The times of the forward and backward peak intensities and the times of the onset of the $\mathrm{BCW}$ and $\mathrm{FEW}$ when calculated using the wave-only and the reservoir-wave models are reported in Table 3. As can be seen from the table, there is no significant difference in timing between the two analyses in all conditions apart from the time of the onset of the FEW that comes earlier when the analysis is performed with $\mathrm{P}_{\mathrm{e}}$, both in control and during the four occlusions

A comparison of wave intensities and reflection indices between occlusion and control conditions yielded a broadly similar pattern. For both the FCW and the FEW there is a slight but statistically significant decrease in the peak values of dI when the occlusion is in the thoracic and diaphragm position and no significant differences when the occlusion is in the more distal locations. This is true for the wave intensity calculated using the measured pressure $\mathrm{dI}$ or the excess pressure $\mathrm{dI}_{\mathrm{e}}$. For the $\mathrm{BCW}$ there is a large and highly significant increase in the dI for the thoracic occlusion, an even larger increase for the diaphragm occlusion and no significant difference for the abdominal and iliac occlusions. Although $\mathrm{dI}_{\mathrm{e}}$ is significantly smaller than $\mathrm{dI}$ for all of the cases, this pattern persists for $\mathrm{dI}_{\mathrm{e}}$; a significant increase for the thoracic occlusion, an even larger increase for the diaphragm occlusion and no differences for the two more distal occlusions.

The reflection index shows this pattern more clearly. For the reflection index calculated using $\mathrm{P}, \mathrm{RI}$ is more than double for the thoracic occlusion, more than triple for the diaphragm occlusion and is not significantly different from control conditions for the 
abdominal and iliac occlusions (Table 2). The reflection index calculated using the $\mathrm{P}_{\mathrm{e}}, \mathrm{RI}_{\mathrm{e}}$, is significantly smaller than the correspondent RI, but follows the same pattern; a large increase for the thoracic occlusion, an even larger increase for the diaphragm occlusion and no significant difference from control conditions for the two more distal occlusions.

\section{Reservoir and excess pressure}

$\mathrm{P}, \mathrm{P}_{\mathrm{r}}$ and $\mathrm{P}_{\mathrm{e}}$ in the ascending aorta for a typical case are shown in Figure 3. As seen in the figure, the aortic pressure increased significantly when the occlusion was in the thoracic aorta. The averaged values of measured, reservoir and excess pulse pressures $\left(\Delta \mathrm{P}, \Delta \mathrm{P}_{\mathrm{r}}\right.$ and $\Delta \mathrm{P}_{\mathrm{e}}$, respectively) and diastolic pressure $\mathrm{P}_{\mathrm{d}}$ for all conditions are reported in Table 1. As can be seen from the table, $\Delta \mathrm{P}$ and $\Delta \mathrm{P}_{\mathrm{r}}$ are significantly higher during thoracic occlusion compared to the control, while $\Delta \mathrm{P}_{\mathrm{e}}$ does not change significantly compared to the control state for all the other occlusion conditions.

Figure 4 shows the relationship between the reservoir pulse pressure $\left(\Delta \mathrm{P}_{\mathrm{r}}\right)$ and the stroke volume $\left(\mathrm{V}_{\text {in }}\right)$ in control condition and during the occlusions for each dog. The Pearson correlation factors between these two parameters were $0.70,0.83,0.87,0.70,0.72$ in control and during thoracic, diaphragm, abdominal and iliac occlusion ( $\mathrm{p}<0.05$ in all conditions). The slope of the linear regression is higher for the thoracic occlusion than control, even higher for the diaphragm occlusion but not significantly different from control for the abdominal and iliac occlusions. A similar relationship is also found between pulse pressure and stroke volume (correlation factors were $0.76,0.85,0.87,0.78,0.74$ for control and occlusions, $\mathrm{p}<0.05$ in all conditions). 


\section{Discussion}

This work compares various hemodynamic parameters in the canine ascending aorta calculated using $\mathrm{P}$ and $\mathrm{P}_{\mathrm{e}}$. The data used in our analysis were originally generated to investigate hemodynamics in the ascending aorta using WIA and the experiment has been designed to provide definitive reflection sites at different locations along the aorta to increase the magnitude of reflected waves seen in the ascending aorta [14]. In the present work, the reservoir-wave model is applied for the first time in these atypical conditions and the similarities and differences between this model and the wave-only model are investigated.

The separation of the pressure waveform using the reservoir-wave technique has shown that $P_{c}$ and the flow waveform are identical in shape and their peaks occured simultaneously as demonstrated in Fig 1. of Wang et al., 2003. However, traditional wave separation indicated that peak of forward wave $\left(\mathrm{P}_{+}\right)$always occured later than peak of the flow waveform. This time difference results in differences only in the onset of the FEW and no significant differences in timing of wave intensity analysis parameters between the two analyses in our experiments. The difference in time of peak $\mathrm{P}$ and $\mathrm{P}_{\mathrm{e}}$ was also considered in relation to the determination of wave speed. The PU-loop method relies on the determination of the slope of the initial linear part of the loop, which usually ends before the time of peak $\mathrm{P}$ or $U$. This means that the differences between $c_{e}$ and $c$ observed in this study, with $c_{e}$ always smaller that $c$, do not depend on the time of pressure $\left(\mathrm{P}\right.$ or $\mathrm{P}_{\mathrm{e}}$ ) or velocity peaks. Nevertheless, wave speed is known to be a direct measure of arterial stiffness and is theoretically expected to have the same value when measred in the same system under the same conditions, even when determined using different techniques. However, a gold standard method for the determination of local wave speed has not been established yet, and therefore it is not possible at this stage to state with confidence which of the tested techhniques in this work yields a more correct value. 
A possible explanation for our results can be found considering the meaning of the reservoir pressure. This pressure component is defined as a time dependent response of the arteries to flow ejected from the heart arising from the net compliance of the arteries. It is assumed to be uniform in shape throughout the system but delayed by a time that is related to the wave travel time from the root of the aorta [28]. Although it appears to be propagating into the arterial system, it is not a simple forward travelling wave but the summation of myriad forward and backward waves produced by the reflection and re-reflection of the waves generated by the ventricle. The theory behind the determination of the wave speed by the slope of the PU-loop assumes that there are only forward waves during early systole. If the reservoir pressure is made up of forward and backward waves then it can be argued that the excess pressure, the difference between the measured and the reservoir pressure, will better satisfy the assumption that only forward waves are included in the $\mathrm{P}_{\mathrm{e}} \mathrm{U}-$-loop and may 1 result in a more plausible estimate of the wave speed. Since the slope of the reservoir pressure is invariably positive in early systole, subtracting it from the measured pressure will reduce the slope of the $\mathrm{P}_{\mathrm{e}} \mathrm{U}$-loop during that time. As a result, the wave speeds estimated from the $\mathrm{P}_{\mathrm{e}} \mathrm{U}$-loop are smaller than those estimated from the PU-loop.

The wave intensities calculated for the three main waves, FCW at early-systole, FEW during late- systole and BCW during mid-systole are reported in Table 2. In every case the magnitude of $\mathrm{dI}_{\mathrm{e}}$ was less than that of the corresponding peak of dI. Despite the decrease in the magnitude of the wave intensity calculated using $P_{c}$, the time and pattern of the magnitudes of the main waves measured during the different occlusions was remarkably similar. The notable exception is the arrival time of the FEW, where the arrival time is earlier when calculated from $\mathrm{dI}_{\mathrm{e}}$ than for $\mathrm{dI}$ (Table 3) because the maximum of $\mathrm{P}_{\mathrm{e}}$ generally occurs earlier than the maximum of $\mathrm{P}$. 
Another finding, common to the two methods, is that the averaged values of RI during diaphragm occlusions are slightly higher than during the thoracic occlusion (Table 2) and in some dogs reflections due to the diaphragm occlusion are bigger than these due to the thoracic occlusion. A possible explanation of our result is that during this proximal occlusion the aortic arch branches (subclavian and brachiocephalic arteries) play a greater role than during the diaphragm occlusion. Westerhof et al. [33] previously suggested that the behaviour of the aorta clamped at the diaphragm level is more similar to a uniform tube with a closed end compared to the aorta occluded at a more proximal location, such as the thoracic level. The authors explained this finding by considering the uniform tube when clamped proximally as "short-circuited" because of the considerable role of the cephalic vessels and collaterals in this condition.

The reflected waves have been used clinically/physiologically as a marker of arterial stiffness [34], thought to play a major role in the shape of the pressure waveform and in the determination of the augmentation index (AIx); a correlate of mortality. However, recent studies questioned the size and role of reflected waves. Sharman et al., [35] found a disparity between the traditional explanation for the shape of the pressure waveform, due to reflected waves, and the reservoir-wave approach. The authors suggested the role of the reflected waves in the determination of AIx may have previously overstated. Davies et al., [24] demonstrated that arterial reservoir increases with age and it is a major determinant of aortic AIx, which they found not to be predominantly a measure of wave reflection. The authors concluded that aortic pressure waveform is more related to the reservoir function than wave reflection. Tyberg et al., reported the magnitude of the peak reflected pressure wave when using the reservoir-wave model is $\sim 6 \%$ of total pressure, where it would be $\sim 30 \%$ of total pressure using the wave-only model [21]. Our results agree with the above studies, and the decrease of the backward compression wave intensity calculated using $\mathrm{P}_{\mathrm{e}}$ is one of the most 
significant results of this study. Similar results about the reduction of backward compression waves using the reservoir-wave model compared to the wave-only model have been recently reported by Mynard et al., [25]. The authors performed WIA in computational and animal data and found lower values of backward compression waves and reflection coefficient when the reservoir-wave system was applied compared to the traditional WIA. These results are in line with our findings. However, they also found bigger backward expansion waves using the reservoir-wave approach that were not present in our work.

Despite the reduction in the magnitude, $\mathrm{dI}_{\mathrm{eBCW}}$ and $\mathrm{dI}_{\mathrm{BCW}}$ showed a similar pattern with significant reflections during the more proximal and no reflections from the more distal occlusion. The small magnitude of the backward travelling waves found using the reservoirwave model can be explained if we consider that the arterial system is well-matched in the forward but not in the backward direction [36,37,38,39]. We calculated the reflection coefficients from the trifurcation of the aortic arch in forward direction as

$$
R_{+}=\frac{Y_{0}-Y_{1}-Y_{2}-Y_{3}}{Y_{0}+Y_{1}+Y_{2}+Y_{3}}
$$

and for the backward direction as

$$
R_{-}=\frac{Y_{3}-Y_{1}-Y_{2}-Y_{0}}{Y_{0}+Y_{1}+Y_{2}+Y_{3}}
$$

where $Y_{0}, Y_{1}, Y_{2}, Y_{3}$, are the characteristic admittances $(Y=1 / Z=A / \rho c)$ for the ascending aorta, brachiocefalic artery, left subclavian artery, and descending aorta, respectively. These values were calculated using the characteristic impedances for the different vessels reported by Cox and Pace [40] in anesthetized dogs in control condition, in which values of vascular impedance have been calculated by averaging between 8 and $15 \mathrm{~Hz}$. We found that the reflection coefficient is 0.02 in the forward direction and -0.48 in the backward direction. This means that approximately half of the energy carried by a backward wave in the thoracic aorta will be reflected at the aortic arch. This may be the main reason for the observation of 
small backward waves at the aortic root, even during the occlusion, using the reservoir-wave model.

The pulse of the reservoir pressure is strongly related to the stroke volume as shown in Figure 4. In particular, a different linear relationship can be observed during occlusion of the aorta at the thoracic and diaphragm level compared to the control for $\mathrm{P}_{\mathrm{r}}$ and $\mathrm{P}_{\mathrm{e}}$, caused by the different pulse pressure in these conditions.

Davies et al. [24] studied the contribution of $\mathrm{P}_{\mathrm{r}}$ and $\mathrm{P}_{\mathrm{e}}$ in humans in relation with age. They found that the contribution of the reservoir pressure to the increase of AIx with age is larger than that of the reflected wave contribution as previously thought $[41,42]$; the increase is largely due to the decrease of the aorta compliance and other elastic vessels. Our results are related to their findings since the increase of pulse pressure due to the thoracic occlusion can be compared to the increase of pressure due to age or to cardiovascular diseases such as hypertension. Our findings confirm that the reservoir pressure makes a larger contribution to the pressure waveform than the excess pressure, shown in Table 1, as previously reported by other authors $[24,43]$.

\section{Conclusion}

The reservoir-wave and the wave-only models produce similar WIA curves, although the magnitudes are strikingly different. Both models lead to the conclusion that aortic occlusions downstream the diaphragm level have little or no effect on hemodynamics in the ascending aorta. The models yield different values of wave speed and different wave magnitudes, despite using the same analytical techniques of the pressure-velocity loop and WIA. The reservoir-wave model always yields lower values for all hemodynamic parameters studied. The small magnitude of $\mathrm{BCW}$ in the aortic root during occlusions, using the reservoir-wave model, could be explained by considering the geometry of the aortic arch which has different magnitude of reflection coefficients in the forward and backward directions, although this 
requires a larger study to confirm this observation. The differences found between the results of wave speed and WIA based on the measured pressure and the reservoir/excess pressures do not mean that the values based on excess pressure are erroneous. In the absence of other independent techniques or evidence it is not currently possible to decide which of the two models compared in this work is more correct. 


\section{References}

[1] Parker KH. A brief history of arterial wave mechanics. Med Biol Eng Comput 2009; 47:111-118.

[2] Hamilton WF and Dow P. An experimental study of the standing waves in the pulse propagated through the aorta. American Journal of Physiology 1938; 125: 48-59.

[3] Taylor MG. Wave Transmission through an Assembly of Randomly Branching Elastic Tubes. Biophysical Journal 1966; 6: 697-716.

[4] Nichols WW and McDonald DA. Wave-velocity in the proximal aorta. Med \& biol. Engng 1972; 10: 327-335.

[5] Sagawa K, Lie RK and Schaefer J. Translation of Otto frank's paper "Die Grundform des arteriellen Pulses" zeitschrift für biologie 37: 483-526 (1899). J.Mol.Cell.Cardiol 1990; 22: $253-254$

[6] Belz GG. Elastic properties and Windkessel function of the human aorta. Cardiovasc.Drugs Ther 1995; 9:73-83.

[7] Westerhof N, Lankhaar J and Westerhof BE. The arterial windkessel. Med Biol Eng Comput 2009; 47:131-141.

[8] Westerhof N, Bosman F, De Vries CJ and Noordergraaf A. Analog studies of the human systemic arterial tree. J Biomech 1969; 2:121-134,IN1,135-136,IN3,137-138,IN5,139-143.

[9] Westerhof N, Elzinga G and Sipkema P. An artificial arterial system for pumping hearts. J.Appl.Physiol 1971; 31:776-781. 
[10] Parker KH, Jones CJH, Dawson JR and Gibson DG. What stops the flow of blood from the heart? Heart Vessels 1988; 4: 241-245.

[11] Parker KH and Jones CJH. Forward and backward running waves in the arteries: Analysis using the method of characteristics. J Biomech Eng 1990; 112:322-326.

[12] Hughes AD and Parker KH. Forward and backward waves in the arterial system: impedance or wave intensity analysis? Med Biol Eng Comput 2009; 47:207-210.

[13] Avolio A, Westerhof BE, Siebes M and Tyberg JV. Arterial hemodynamics and wave analysis in the frequency and time domains: an evaluation of the paradigms. Med Biol Eng Comput 2009; 47:107-110.

[14] Khir AW and Parker KH. Wave intensity in the ascending aorta: Effects of arterial occlusion. J Biomech 2005; 38:647-655.

[15] Zambanini A, Cunningham SL, Parker KH, Khir AW, Thom SAM and Hughes AD. Wave-energy patterns in carotid, brachial, and radial arteries: A noninvasive approach using wave-intensity analysis. Am J Physiol Heart Circ Physiol 2005; 289: H270-H276.

[16] Borlotti A, Khir AW, Rietzschel ER, De Buyzere ML, Vermeersch S, and Segers P. Non-invasive determination of local pulse wave velocity and wave intensity: changes with age and gender in the carotid and femoral arteries of healthy human. J Appl Physiol 2012; 113:727-735.

[17] Wang JJ, O'Brien AB, Shrive NG, Parker KH and Tyberg JV. Time-domain representation of ventricular-arterial coupling as a windkessel and wave system. Am J Physiol Heart Circ Physiol 2003; 284:H1358-H1368. 
[18] Wang JJ, Flewitt JA, Shrive NG, Parker KH and Tyberg JV. Systemic venous circulation. Waves propagating on a windkessel: Relation of arterial and venous windkessels to systemic vascular resistance. Am J Physiol Heart Circ Physiol 2006; 290:H154-H162.

[19] Aguado-Sierra J, Alastruey J, Wang JJ, Hadjiloizou N, Davies J and Parker KH. Separation of the reservoir and wave pressure and velocity from measurements at an arbitrary location in arteries. Proc Inst Mech Eng Part H J Eng Med 2008; 222:403-416.

[20] Davies JE, Hadjiloizou N, Leibovich D, Malaweera A, Alastruey-Arimon J, Whinnett ZI, et al. Importance of the aortic reservoir in determining the shape of the arterial pressure waveform - The forgotten lessons of Frank. Artery Res 2007; 1:40-45.

[21] Tyberg JV, Davies JE, Wang Z, Whitelaw WA, Flewitt JA, Shrive NG, et al. Wave intensity analysis and the development of the reservoir-wave approach. Med Biol Eng Comput 2009; 47:221-232.

[22] Ochi H, Shimada T, Ikuma I, Morioka S and Moriyama K. Effect of a decrease in aortic compliance on the isovolumic relaxation period of the left ventricle in man. Am J Noninvasive Cardiol 1991; 5:149-154.

[23] Watanabe H, Ohtsuka S, Kakihana M and Sugishita Y. Coronary circulation in dogs with an experimental decrease in aortic compliance. J Am Coll Cardiol 1993; 21:1497-1506.

[24] Davies JE, Baksi J, Francis DP, Hadjiloizou N, Whinnett ZI, Manisty CH, et al. The arterial reservoir pressure increases with aging and is the major determinant of the aortic augmentation index. Am J Physiol Heart Circ Physiol 2010; 298:H580-H586. 
[25] Mynard JP, Penny DJ, Davidson MR and Smolich JJ. The reservoir-wave paradigm introduces error into arterial wave analysis: a computer modelling and in-vivo study. J Hypertens 2012; 30:734-743.

[26] Segers P, Swillens A, Vermeersch S. Reservations on the reservoir. J Hypertens 2012; 30:676-678.

[27] Wang JJ, Shrive NG, Parker KH, Hughes, AD and Tyberg JV. Wave propagation and reflection in the canine aorta: analysis using a reservoir-wave approach. Can J Cardiol 2011; 27:389.e1-389.e10.

[28] Parker KH, Alastruey J and Stan G. Arterial reservoir-excess pressure and ventricular work. Med Biol Eng Comput 2012; 50:419-424.

[29] Khir AW, O'Brien A, Gibbs JSR and Parker KH. Determination of wave speed and wave separation in the arteries. J Biomech 2001; 34:1145-1155.

[30] Westerhof N, Sipkema P, Van Den Bos GC, and Elzinga G. Forward and backward waves in the arterial system. Cardiovasc Res 1972; 6648-656.

[31] Van Den Bos GC, Westerhof N, Elzinga G and Sipkema P. Reflection in the systemic arterial system: effects of aortic and carotid occlusion. Cardiovasc Res 1976; 10:565-573.

[32] Swalen MJP and Khir AW. Resolving the time lag between pressure and flow for the determination of local wave speed in elastic tubes and arteries. J Biomech 2009; 42: 15741577. 
[33] Westerhof N, Elzinga G and Van Den Bos GC. Influence of central and peripheral changes on the hydraulic input impedance of the systemic arterial tree. Med Biol Eng 1973; 11:710-723.

[34] O'Rourke MF and Nichols WW. Aortic diameter, aortic stiffness, and wave reflection increase with age and isolated. Hypertension 2005; 45:652-658.

[35] Sharman JE, Davies JE, Jenkins C, Marwick TH. Augmentation Index, Left Ventricular Contractility, and Wave Reflection. Hypertension 2009; 54:1099-1105.

[36] Gosling RG, Newman DL, Bowden NL and Twinn KW. The area ratio of normal aortic junctions. Aortic configuration and pulse-wave reflection. Br J Radiol 1971; 44:850-853.

[37] Newman DL, Bowden LR, Gosling RG and Wille SD. Impedance of aortic bifurcation grafts. J Cardiovasc Surg 1972; 13:175-180.

[38] Greenwald SE and Newman DL. Impulse propagation through junctions. Med Biol Eng Comput 1982; 20:343-350.

[39] Papageorgiou GL, Jones BN, Redding VJ and Hudson N. The area ratio of normal arterial junctions and its implications in pulse wave reflections. Cardiovasc Res 1990; 24: 478-484.

[40] Cox RH and Pace JB. Pressure flow relations in the vessels of the canine aortic arch. Am J Physiol 1975; 228:1-10.

[41] Mitchell GF, Parise H, Benjamin EJ, Larson MG, Keyes MJ, Vita JA, et al. Changes in arterial stiffness and wave reflection with advancing age in healthy men and women- The Framingham Heart Study. Hypertension 2004; 43:1239-1245. 
[42] Weber T, Auer J, O’Rourke MF, Kvas E, Lassnig E, Berent R, et al. Arterial stiffness, wave reflections, and the risk of coronary artery disease. Circulation 2004; 109:184-189.

[43] Vermeersch SJ, Rietzschel ER, De Buyzere ML, Van Bortel LM, Gillibert TC, Verdonk PR and Segers P. The reservoir pressure concept: the 3-element windkessel model revisited? Application to the Asklepios population study. J Eng Math 2009; 64:417-428. 


\section{Figure legends}

Figure 1. a) Typical examples of PU-loop in control (gray) and during thoracic occlusion (black). b) Examples of $\mathrm{P}_{\mathrm{e}} \mathrm{U}$-loop in control (gray) and during thoracic occlusion (black). The dashed black line is the linear part of the loop used to calculate the wave speed. Note the different scales between a and $b$.

Figure 2. a and b) Typical example of wave intensity analysis in control condition calculated with $\mathrm{P}$ and $\mathrm{P}_{\mathrm{e}}$, respectively. $\mathrm{c}$ and $\mathrm{d}$ ) wave intensity analysis during the thoracic occlusion using $\mathrm{P}$ and $\mathrm{P}_{\mathrm{e}}$, respectively . Black lines are forward intensities $\left(\mathrm{dI}_{+}\right.$and $\mathrm{dI}_{\left.\mathrm{e}^{+}\right)}$and gray lines backward intensities ( $\mathrm{dI}_{-}$and $\mathrm{dI}_{\mathrm{e}_{-}}$). Solid black arrows indicate the onset of the forward compression wave (FCW), gray arrows indicate the onset of the backward compression wave $(\mathrm{BCW})$ and the dashed black arrow show the onset of the forward expansion wave (FEW).

Figure 3. Left panel: a) Measured pressure ( $\mathrm{P}$, dashed black) separated into its forward $\left(\mathrm{P}_{+}\right.$, solid black) and backward ( $\mathrm{P}_{-}$, gray) components; b) excess pressure $\left(\mathrm{P}_{\mathrm{e}}\right.$, thin black) separated into its forward $\left(\mathrm{P}_{\mathrm{e}+}\right.$, solid black) and backward ( $\mathrm{P}_{\mathrm{e}-}$, gray) components (right axis), measured pressure ( $\mathrm{P}$, dashed black) and reservoir $\left(\mathrm{P}_{\mathrm{r}}\right.$, dashed gray) component (left axis) in control conditions. $\mathrm{P}_{\mathrm{d}}$ in this case is $63 \mathrm{mmHg}$.

Right panel: c) Measured pressure ( $\mathrm{P}$, dashed black) separated into its forward $\left(\mathrm{P}_{+}\right.$, solid black) and backward ( $\mathrm{P}_{\text {-, gray }}$ components; $\left.\mathrm{d}\right)$ excess pressure $\left(\mathrm{P}_{\mathrm{e}}\right.$, thin black) separated into its forward ( $\mathrm{P}_{\mathrm{e}+}$, solid black) and backward ( $\mathrm{P}_{\mathrm{e}-}$, gray) components (right axis), measured pressure $\left(\mathrm{P}\right.$, dashed black) and reservoir $\left(\mathrm{P}_{\mathrm{r}}\right.$, dashed gray) component (left axis) during thoracic occlusion. $\mathrm{P}_{\mathrm{d}}$ in this case is $100 \mathrm{mmHg}$.

Figure 4. Relationship between reservoir pulse pressure $\left(\Delta \mathrm{P}_{\mathrm{r}}\right)$ and ejected volume $\left(\mathrm{V}_{\text {in }}\right)$ in control condition and during occlusions at the thoracic (a), diaphragm (b), abdominal (c) and iliac (d) level. Note that in (a), for a given stroke volume $\Delta \mathrm{Pr}$ is greater because the effective aortic volume was smaller due to the occlusion. 

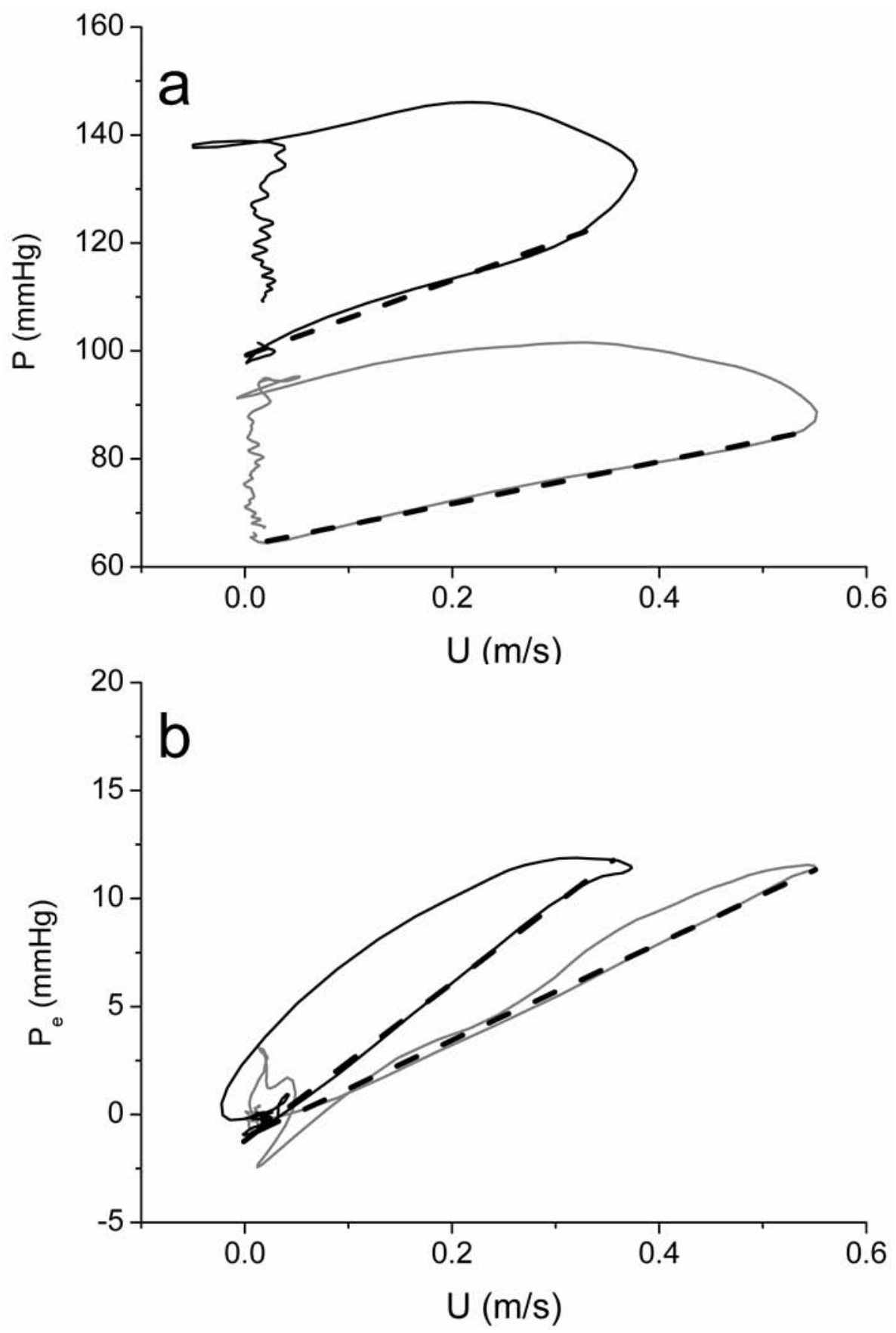
Control
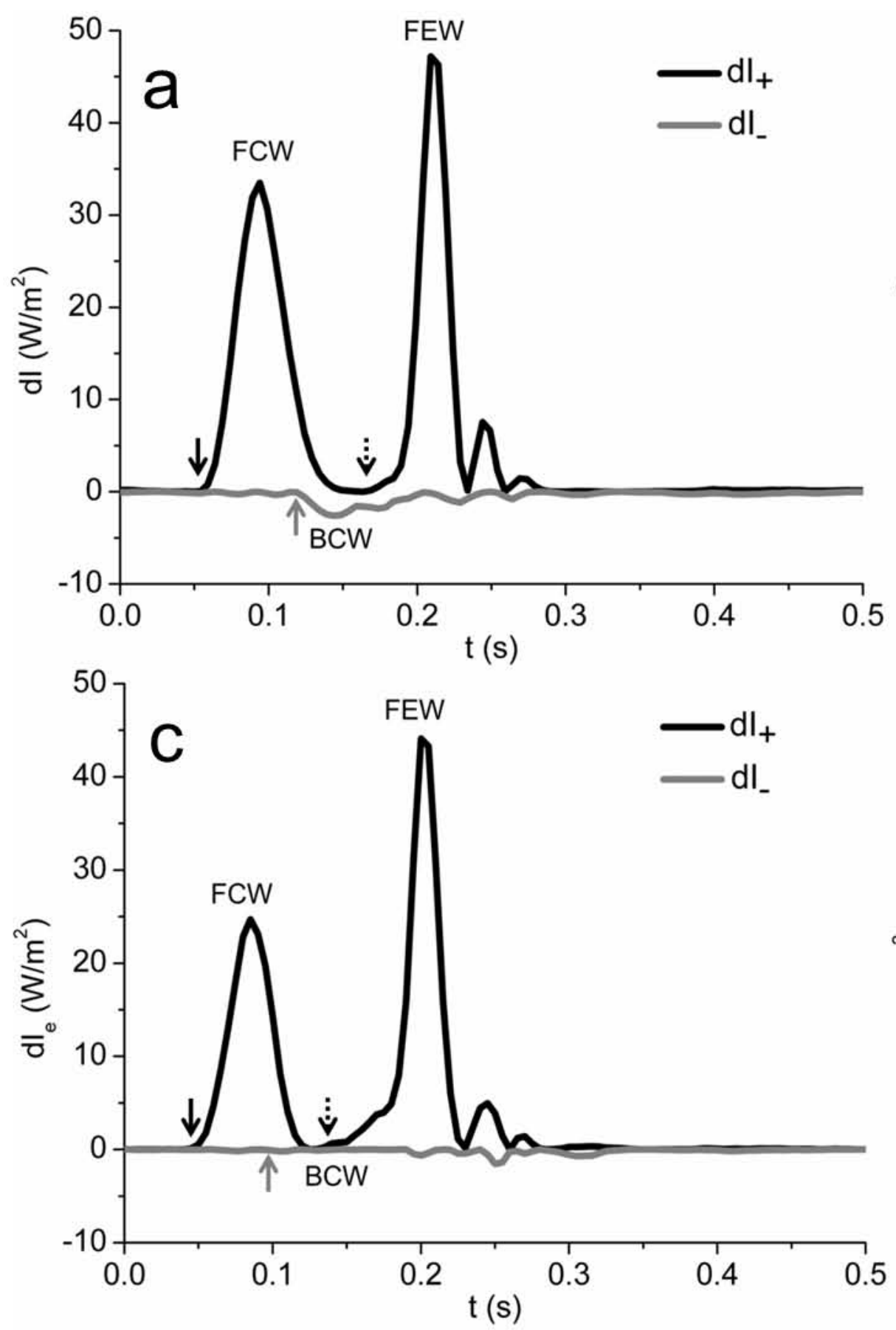

Thoracic occlusion
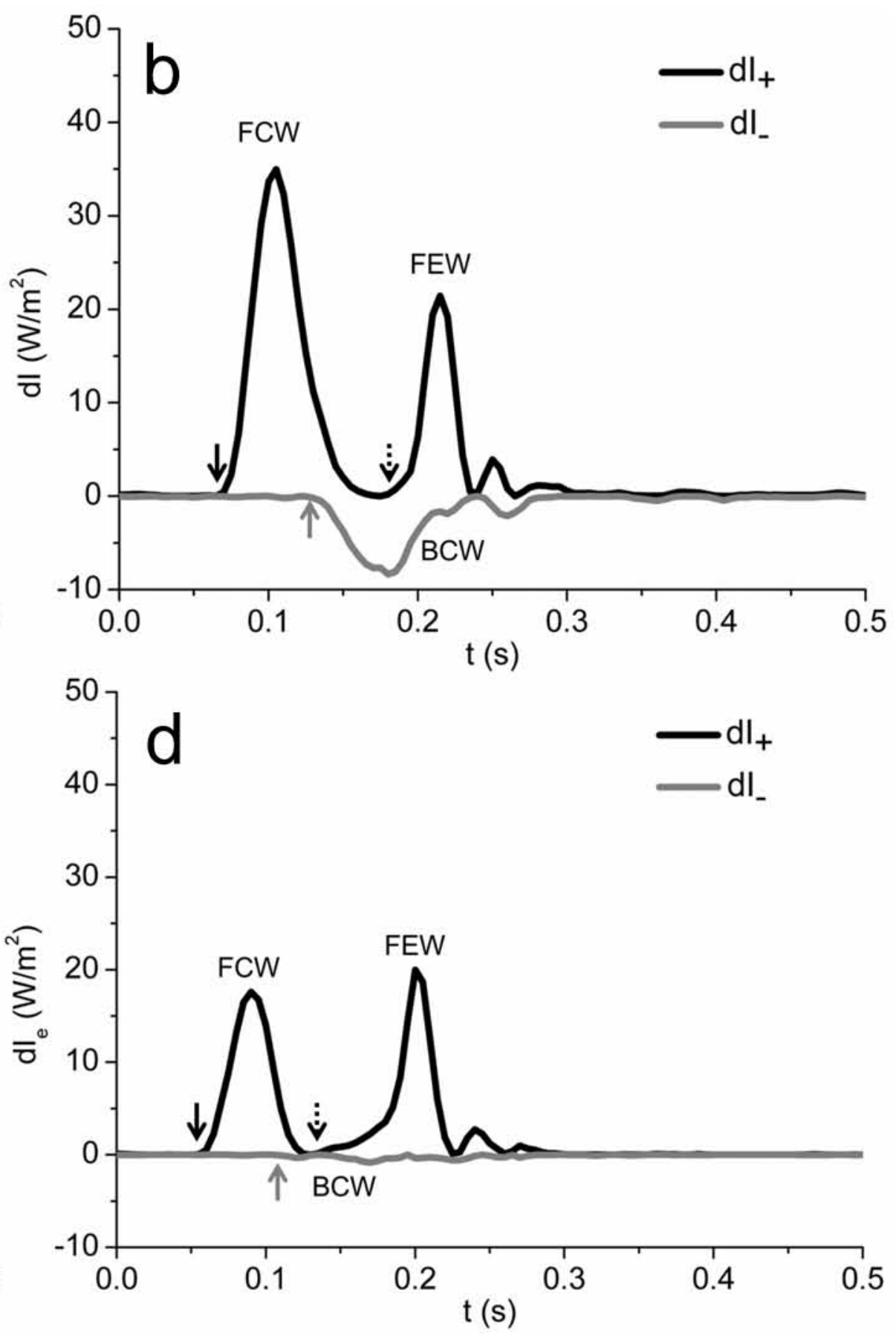


\section{Control}
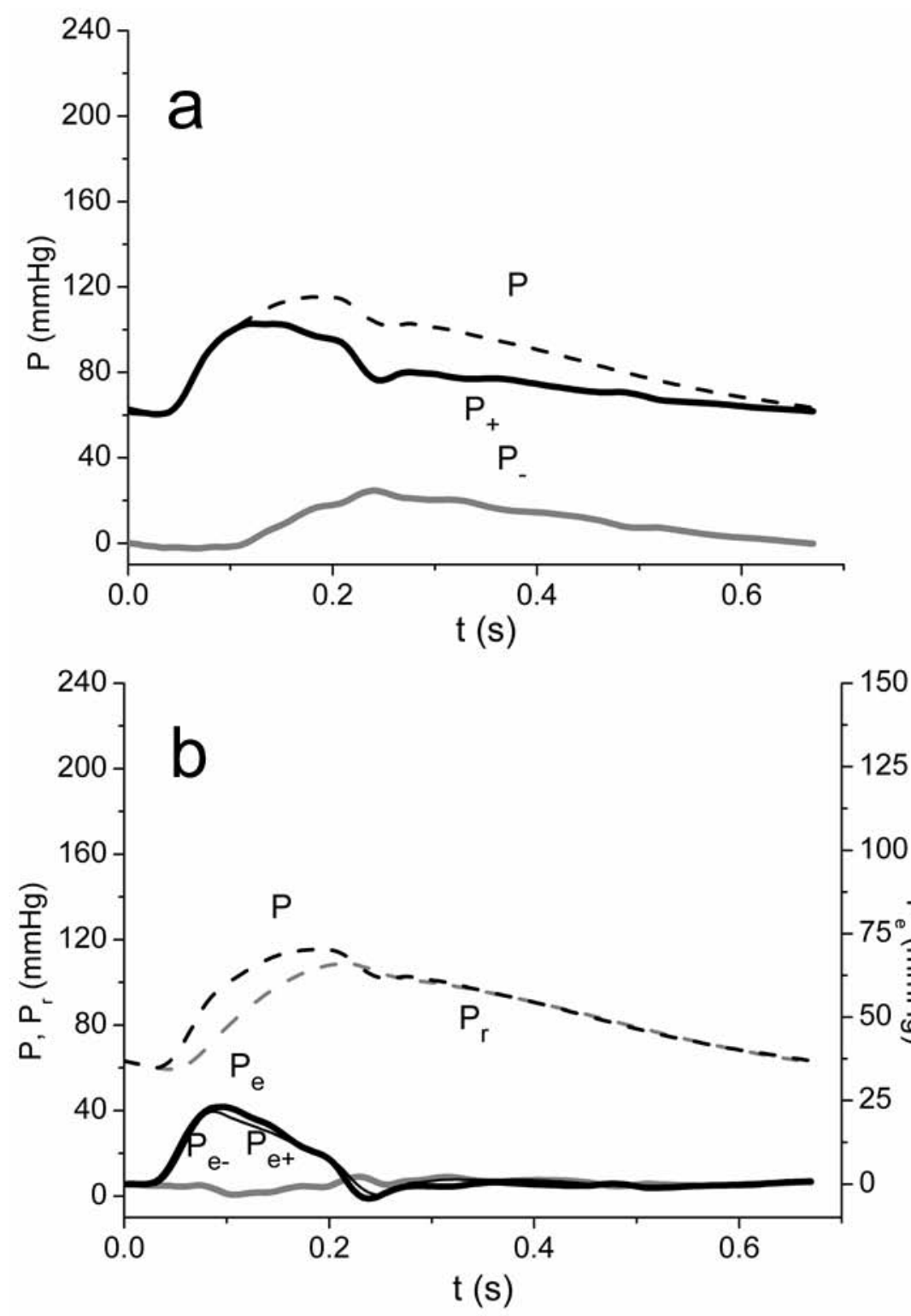

\section{Thoracic occlusion}
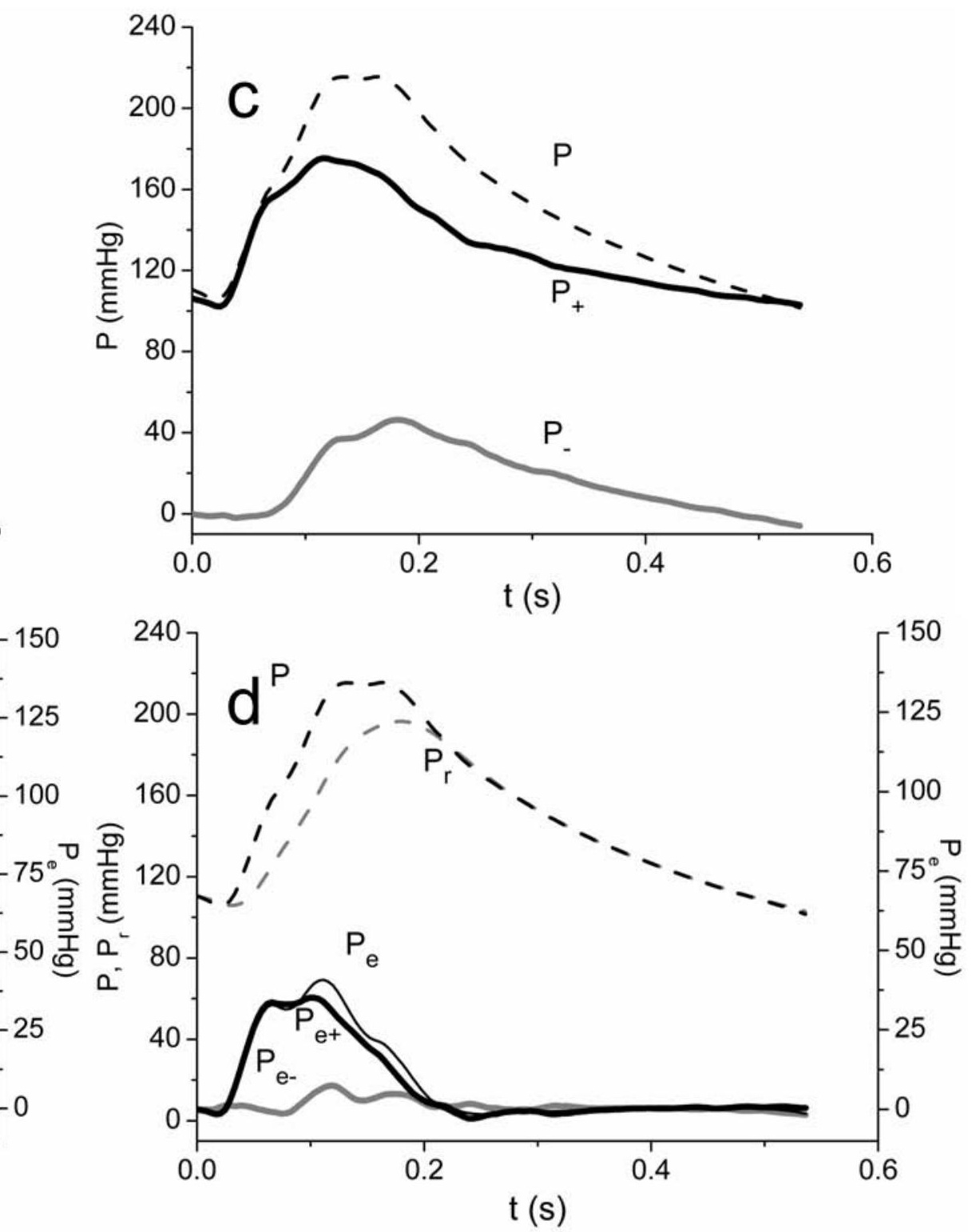


Table 1. Proximal aortic pulse pressures and diastolic pressure at control and during occlusion at the levels of the thoracic, diaphragm, abdominal and iliac arteries.

\begin{tabular}{cccccc}
\hline \hline $\begin{array}{c}\text { Pressure } \\
(\mathrm{mmHg})\end{array}$ & $\begin{array}{c}\text { Control } \\
(\mathrm{n}=11)\end{array}$ & $\begin{array}{c}\text { Thoracic } \\
(\mathrm{n}=10)\end{array}$ & $\begin{array}{c}\text { Diaphragm } \\
(\mathrm{n}=11)\end{array}$ & $\begin{array}{c}\text { Abdominal } \\
(\mathrm{n}=11)\end{array}$ & $\begin{array}{c}\text { Iliac } \\
(\mathrm{n}=9)\end{array}$ \\
\hline$\Delta \mathrm{P}$ & $37 \pm 11$ & $64 \pm 18^{* *}$ & $40 \pm 17$ & $33 \pm 10$ & $37 \pm 10$ \\
$\Delta \mathrm{P}_{+}$ & $31 \pm 10$ & $43 \pm 10^{*}$ & $27 \pm 11$ & $28 \pm 10$ & $31 \pm 10$ \\
$\Delta \mathrm{P}_{-}$ & $15 \pm 5$ & $27 \pm 8^{* *}$ & $19 \pm 8$ & $15 \pm 5$ & $16 \pm 6$ \\
$\Delta \mathrm{P}_{\mathrm{r}}$ & $30 \pm 9$ & $52 \pm 20^{*}$ & $35 \pm 16$ & $28 \pm 8$ & $28 \pm 9$ \\
$\Delta \mathrm{P}_{\mathrm{e}}$ & $20 \pm 8$ & $21 \pm 7$ & $17 \pm 6$ & $17 \pm 8$ & $21 \pm 9$ \\
$\mathrm{P}_{\mathrm{d}}$ & $83 \pm 19$ & $112 \pm 21^{* *}$ & $104 \pm 21^{* *}$ & $88 \pm 18$ & $82 \pm 0$
\end{tabular}

Values are mean \pm SD. ${ }^{*}$ indicates $\mathrm{p}<0.05$ compared to the control and ${ }^{* *}$ indicates $\mathrm{p}<0.001$ compared to the control. $\Delta \mathrm{P}, \Delta \mathrm{P}_{+}$and $\Delta \mathrm{P}_{\mathrm{r}}$ are calculated as the difference between the peak and the diastolic values. 
Table 2. Averaged values of wave speed and intensity parameters calculated using $\mathrm{P}_{\mathrm{e}}$ and $\mathrm{P}$ and their percentage ratio at control and during occlusion at the levels of the thoracic, diaphragm, abdominal and iliac arteries.

\begin{tabular}{cccccc}
\hline & Control & Thoracic & Diaphragm & Abdominal & Iliac \\
\hline $\mathrm{c}(\mathrm{m} / \mathrm{s})$ & $5.8 \pm 1.8$ & $9.9 \pm 2.6^{*}$ & $5.8 \pm 1.3$ & $5.8 \pm 1.5$ & $5.9 \pm 3.0$ \\
$\mathrm{c}_{\mathrm{e}}(\mathrm{m} / \mathrm{s})$ & $4.1 \pm 1.7^{\xi}$ & $5.5 \pm 1.6^{\xi}$ & $4.0 \pm 1.2^{\xi}$ & $3.7 \pm 1.3^{\xi}$ & $4.3 \pm 1.6^{\xi}$ \\
$\mathrm{c}_{\mathrm{e}} / \mathrm{c}(\%)$ & 71 & 56 & 69 & 64 & 73 \\
$\mathrm{dI}_{\mathrm{FCW}}\left(\mathrm{W} / \mathrm{m}^{2}\right)$ & $51.2 \pm 47.4$ & $34.3 \pm 27.2^{*}$ & $34.9 \pm 38.2^{*}$ & $49.2 \pm 48.3$ & $53.6 \pm 49.8$ \\
$\mathrm{dI}_{\mathrm{eFCW}}\left(\mathrm{W} / \mathrm{m}^{2}\right)$ & $32.2 \pm 31.7^{\xi}$ & $24.4 \pm 19.3^{\xi, *}$ & $23.4 \pm 25.2^{\xi, *}$ & $29.5 \pm 34.8^{\xi}$ & $32.2 \pm 33.2^{\xi}$ \\
$\mathrm{dI}_{\mathrm{eFCW}} / \mathrm{dI}_{\mathrm{FCW}}(\%)$ & 63 & 71 & 67 & 60 & 60 \\
$\mathrm{dI}_{\mathrm{FEW}}\left(\mathrm{W} / \mathrm{m}^{2}\right)$ & $34.7 \pm 15.5$ & $22.5 \pm 12.6^{*}$ & $23.9 \pm 12.6^{*}$ & $29.3 \pm 14.8$ & $41.4 \pm 20.9$ \\
$\mathrm{dI}_{\mathrm{eFEW}}\left(\mathrm{W} / \mathrm{m}^{2}\right)$ & $25.7 \pm 13.3^{\xi}$ & $21.6 \pm 12.1$ & $20.8 \pm 10.4$ & $20.5 \pm 13.5^{\xi}$ & $27.7 \pm 16.3^{\xi}$ \\
$\mathrm{dI}_{\mathrm{eFEW}} / \mathrm{dI}_{\mathrm{FEW}}(\%)$ & 74 & 96 & 87 & 70 & 67 \\
$\mathrm{dI}_{\mathrm{BCW}}\left(\mathrm{W} / \mathrm{m}^{2}\right)$ & $4.4 \pm 3.5$ & $8.7 \pm 7.7^{*}$ & $10.2 \pm 9.0^{*}$ & $4.1 \pm 3.4$ & $4.3 \pm 4.0$ \\
$\mathrm{dI}_{\mathrm{eBCW}}\left(\mathrm{W} / \mathrm{m}^{2}\right)$ & $1.1 \pm 1.6^{\xi \xi}$ & $2.0 \pm 2.5^{\xi \xi * *}$ & $2.4 \pm 2.8^{\xi \xi * *}$ & $1.3 \pm 2.0^{\xi \xi}$ & $1.3 \pm 2.2^{\xi}$ \\
$\mathrm{dI}_{\mathrm{eBCW}} / \mathrm{dI}_{\mathrm{BCW}}(\%)$ & 24 & 23 & 24 & 32 & 31 \\
$\mathrm{RI}$ & $0.10 \pm 0.05$ & $0.25 \pm 0.15^{*}$ & $0.33 \pm 0.12^{* *}$ & $0.11 \pm 0.06$ & $0.09 \pm 0.04$ \\
$\mathrm{RI} \mathrm{I}_{\mathrm{e}}$ & $0.03 \pm 0.03^{\xi \xi}$ & $0.07 \pm 0.04^{\xi \xi, * *}$ & $0.12 \pm 0.06^{\xi \xi, *}$ & $0.04 \pm 0.03^{\xi}$ & $0.03 \pm 0.02^{\xi}$ \\
$\mathrm{RI} \mathrm{I}_{\mathrm{e}} / \mathrm{RI}$ & 29 & 30 & 36 & 37 & 30 \\
\hline
\end{tabular}

Values are mean $\pm \mathrm{SD} .{ }^{*}$ indicates $\mathrm{p}<0.05$ compared to the control and ${ }^{* *}$ indicates $\mathrm{p}<0.001$ compared to the control. ${ }^{\xi}$ indicates $\mathrm{p}<0.05$ compared to the wave-only model and ${ }^{\xi \xi}$ indicates $\mathrm{p}<0.001$ compared to the wave-only model. 
Table 3. Timing of the onset and peak of the main waves at control and during occlusion at the levels of the thoracic, diaphragm, abdominal and iliac arteries.

\begin{tabular}{cccccc}
\hline \hline Time $(\mathrm{ms})$ & Control & Thoracic & Diaphragm & Abdominal & Iliac \\
\hline $\mathrm{t}_{\mathrm{FCW}}$ & $29 \pm 4$ & $34 \pm 5$ & $30 \pm 5$ & $28 \pm 4$ & $28 \pm 6$ \\
$\mathrm{t}_{\mathrm{eFCW}}$ & $32 \pm 3$ & $32 \pm 5$ & $33 \pm 2$ & $31 \pm 3$ & $34 \pm 3$ \\
$\mathrm{t}_{\mathrm{BCW}}$ & $92 \pm 12$ & $103 \pm 9$ & $96 \pm 15$ & $89 \pm 14$ & $91 \pm 23$ \\
$\mathrm{t}_{\mathrm{eBCW}}$ & $83 \pm 14$ & $98 \pm 9$ & $97 \pm 14$ & $81 \pm 19$ & $81 \pm 27$ \\
$\mathrm{t}_{\mathrm{FEW}}$ & $161 \pm 25$ & $157 \pm 19$ & $157 \pm 36$ & $150 \pm 34$ & $164 \pm 23$ \\
$\mathrm{t}_{\mathrm{eFEW}}$ & $161 \pm 25$ & $157 \pm 24$ & $157 \pm 27$ & $151 \pm 35$ & $165 \pm 22$ \\
$\mathrm{t}_{\mathrm{BCW} \text { (N) }}$ & $56 \pm 7$ & $41 \pm 9$ & $48 \pm 6$ & $56 \pm 11$ & $55 \pm 13$ \\
$\mathrm{t}_{\mathrm{eBCW}}$ & $51 \pm 6$ & $43 \pm 5$ & $46 \pm 3$ & $49 \pm 4$ & $54 \pm 7$ \\
$\mathrm{t}_{\mathrm{FEW} \text { onset }}$ & $87 \pm 12$ & $108 \pm 12$ & $109 \pm 21$ & $77 \pm 14$ & $84 \pm 14$ \\
$\mathrm{t}_{\mathrm{eFEW}}$ & $71 \pm 8^{\xi \xi}$ & $83 \pm 14^{\xi \xi}$ & $74 \pm 18^{\xi \xi}$ & $65 \pm 9^{\xi \xi}$ & $72 \pm 6^{\xi}$
\end{tabular}

Values are mean \pm SD. ${ }^{\xi}$ indicates $\mathrm{p}<0.05$ compared to the wave-only model and ${ }^{\xi \xi}$ indicates $\mathrm{p}<0.001$ compared to the wave-only model. 